\title{
Causes of portal hypertension in children.
}

1. MBBS

Post Graduate Resident, Department of Pediatric Medicine, The Children's Hospital \& ICH, Multan.

2. MBBS, FCPS (Pediatric Medicine) Associate Professor Pediatric Medicine

The Children's Hospital \& ICH Multan.

3. MBBS, FCPS (Pediatric Medicine) Assistant Professor Pediatric Medicine

The Children's Hospital \& ICH Multan.

4. MBBS, FCPS (Pediatric Medicine) Senior Registrar, Department of Pediatric Medicine, Ghazi Khan Medical College, Dera Ghazi Khan.

Correspondence Address: Dr. Asim Khurshid

Department of Pediatric Medicine The Children's Hospital \& ICH, Multan. asimkhurshiddr@gmail.com

Article received on:

30/06/2020

Accepted for publication:

$31 / 08 / 2020$

\author{
Kausar Aftab', Asim Khurshid², Ayesha Fayyaz ${ }^{3}$, Irum Jabeen ${ }^{4}$
}

ABSTRACT... Objective: To determine different causes of portal hypertension in children. Study Design: Cross Sectional study. Setting: Department of Pediatric Medicine, Department of Pediatric Gastroenterology and Department of Medical Emergency, The Children's Hospital and Institute of Child Health, Multan. Period: $3^{\text {rd }}$ April 2019 to $2^{\text {nd }}$ October 2019. Material \& Methods: A total of 71 children presenting with portal hypertension aged 1 month to 15 years of either gender were included. Newborns or children with congenital heart diseases were excluded. Patient samples were collected for complete blood counts and liver function tests, Ultrasound Abdomen and color Doppler ultrasonography were done for portal vein pressure to determine various causes of portal hypertension. Results: Overall, mean age was $9.00 \pm 3.64$ years. Out of the 71 patients, 51 (71.83\%) were male and $20(28.17 \%)$ were females. Different causes of portal hypertension were portal vein thrombosis in 48 (67.61\%), liver cirrhosis in 14 $(19.72 \%)$ and biliary atresia in 9 (12.68\%) children. Conclusion: Among children having portal hypertension, portal vein thrombosis was noted to be the commonest cause followed by liver cirrhosis and biliary atresia.

\section{Key words: $\quad$ Biliary Atresia, Liver Cirrhosis, Portal Vein Thrombosis.}

Article Citation: Aftab K, Khurshid A, Fayyaz A, Jabeen I. Causes of portal hypertension in children. Professional Med J 2021; 28(10):1489-1494. https://doi.org/10.29309/TPMJ/2021.28.10.5376

\section{INTRODUCTION}

Portal hypertension $(\mathrm{PH})$ transpires when raised portal resistance with or without increased portal blood flow. Usually, portal venous system is having low baseline portal pressure ranging 7 to $10 \mathrm{mmHg} .{ }^{1,2}$ History and physical examination help clinical diagnosis of $\mathrm{PH}$. Commonest clinical manifestations of $\mathrm{PH}$ in children that may need referrals are upper gastrointestinal bleeding (UGIB) and splenomegaly. ${ }^{3}$ Extrahepatic portal vein obstruction (EHPVO) might present from the age of 6 years to adulthood however it is generally considered a childhood disorder. UGIB is considered to be the most frequent early clinical manifestation of EHPVO among children. ${ }^{4,5}$ Esophageal varices is found to present among $90-95 \%$ cases while gastric varices is noted in 35$40 \% .{ }^{1}$ It has also been seen that around $80 \%$ of the children having EHPVO are estimated to have minimum 1 episode of UGIB throughout their lifetime. ${ }^{6}$
$\mathrm{PH}$ usually indicates advanced liver disease and increasing chances of fatal complications like hemorrhage linked to esophageal varices. ${ }^{7}$ Portal vein thrombosis (PVT) is a frequent etiology behind $\mathrm{PH}$ among pediatric age groups. ${ }^{8}$ Imanieh $\mathrm{MH}$ and colleagues noted PVT to be the cause of $\mathrm{PH}$ in $74.2 \%$ of the cases while cirrhosis was found in $26.7 \%$ and biliary atresia $24.4 \% .^{9}$

We aimed this study to document the different causes of $\mathrm{PH}$. Our findings are thought to generate useful data about causes of $\mathrm{PH}$ in children admitted to Tertiary care Hospital and may provide useful guidelines for investigations and management of these patients. This will improve outcomes, provide relief to the suffering families and hospital authorities in terms of availability of more space in the wards.

\section{MATERIAL \& METHODS}

This descriptive, cross-sectional study was done at The Department of Pediatric Medicine, 
Department of Pediatric Gastroenterology and Department of Medical Emergency, "The Children's Hospital and Institute of Child Health, Multan", from 3rd April 2019 to 2nd October 2019. Approval from "Institutional Ethical Committee" was taken for this study.

A sample size of 71 children was estimated by employing formula " $n=z^{2} p q / d^{2}$ " where $z=1.96$, $p=24.4 \%^{9}$ (frequency of Biliary Artesia in children with portal hypertension), $q=100-p, d=10 \%$.

Non-probability, consecutive sampling technique was adopted. Inclusion Criteria was children aged 1 month - 15 years of both gender, presenting with $\mathrm{PH}$ irrespective of disease duration. All newborns aged less than 28 days, having congenital abnormalities like congenital heart diseases were excluded. $\mathrm{PH}$ was defined as portal pressure $>$ $10 \mathrm{mmHg}$ with Doppler ultrasound, diagnosed by a sonologist having minimum 3 year experience after FCPS Radiology.

A special proforma was made to note all the study findings. Informed consent was sought from parents/guardians of study participants. Detailed history and physical examination was conducted. Once registered in the study, patient samples were collected for complete blood counts, liver function tests including Serum Bilirubin, Alanine Aminotransferase (ALT), Serum Albumin and prothrombin time (PT) / Activated Partial Thromboplastin Time (APTT), Ultrasound Abdomen and Color Doppler USG for Portal vein Pressure to determine causes of portal hypertension such as portal vein thrombosis (PVT), Liver cirrhosis and biliary atresia. Portal vein thrombosis was defined as thrombus in portal vein leading to no blood flow as diagnosed on color Doppler ultrasound. Liver cirrhosis was labeled as presence of all of the following: a) coarse parenchymal echogenicity and irregular margins of liver on Ultrasound abdomen b) Serum Albumin $<3.5 \mathrm{~g} / \mathrm{dl}$ c) Serum ALT $>40 \mathrm{IU} / \mathrm{L}$. Biliary atresia as labeled as congenital absence or closure of the major bile duct with triangular cord sign on Ultrasound deemed as positive.

Data entry and analysis was preceded by using
SPSS-20. Mean and standard deviation were calculated for age, portal pressure and duration of illness. Frequencies and percentages were calculated for categorical variables like age groups, gender, residential status, maternal literacy level, family income and causes of portal hypertension. Effect modifiers like age, gender, residential status, monthly family income, mother's educational level and duration of illness were controlled through stratification. Post stratification chi-square test was applied to see their effect on outcome (causes of portal hypertension) considering $p$-value $\leq 0.05$ as significant.

\section{RESULTS}

Out of the 71 patients, 51 (71.83\%) were male and $20(28.17 \%)$ were female, with male to female ratio of 2.6:1. Age range in this study was from 1 month to 15 years with mean age of $9.00 \pm 3.64$ years. Majority of the patients $43(60.56 \%)$ were between 8 to 15 years while remaining 28 (39.44\%) were below 8 years of age. Overall, mean disease duration was noted to be $3.68 \pm 1.67$ years.

Figure-1 shows different causes of portal hypertension in children as portal vein thrombosis in 48 (67.61\%), liver cirrhosis in 14 (19.72\%) and biliary atresia in 09 (12.68\%).

Stratification of different causes of portal hypertension with respect to study variables are shown in Table-I to VI.

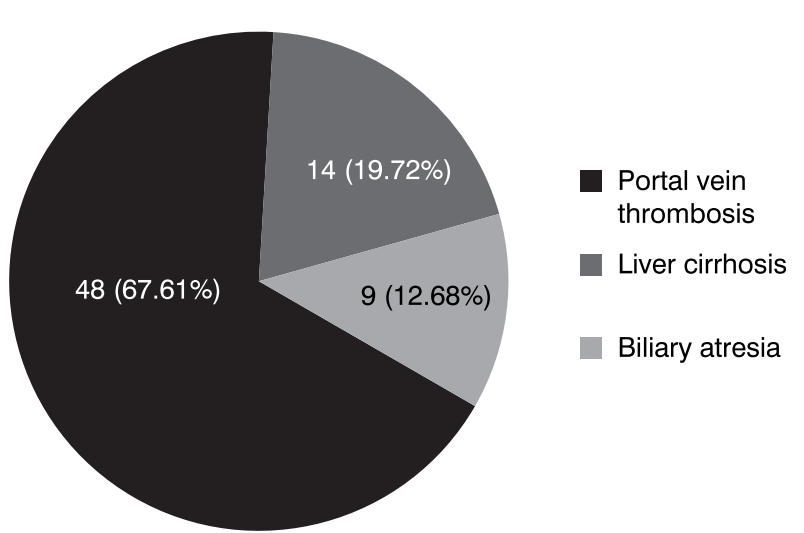

Figure-1. Different causes of portal hypertension in children 


\begin{tabular}{|c|c|c|c|c|}
\hline & & $1-7$ Years $(n=28)$ & 8-15 Years $(n=43)$ & P-Value \\
\hline \multirow{2}{*}{ Portal vein thrombosis } & Yes & $19(67.86 \%)$ & $29(67.44 \%)$ & \multirow{2}{*}{0.971} \\
\hline & No & 09 (32.14\%) & $14(32.56 \%)$ & \\
\hline \multirow{2}{*}{ Liver cirrhosis } & Yes & $06(21.43 \%)$ & $08(18.60 \%)$ & \multirow{2}{*}{0.770} \\
\hline & No & 22 (78.57\%) & 35 (81.40\%) & \\
\hline \multirow{2}{*}{ Biliary atresia } & Yes & $03(10.71 \%)$ & 06 (13.95\%) & \multirow{2}{*}{0.688} \\
\hline & No & $25(89.29 \%)$ & $37(86.05 \%)$ & \\
\hline
\end{tabular}

Table-I. Causes of portal hypertension with respect to age.

\begin{tabular}{|c|c|c|c|c|}
\hline & & Male $(n=51)$ & Female $(n=20)$ & P-Value \\
\hline \multirow{2}{*}{ Portal vein thrombosis } & Yes & $35(68.63 \%)$ & $13(65.0 \%)$ & \multirow{2}{*}{0.769} \\
\hline & No & $16(31.37 \%)$ & $07(35.0 \%)$ & \\
\hline \multirow{2}{*}{ Liver cirrhosis } & Yes & $09(17.65 \%)$ & $05(25.0 \%)$ & \multirow{2}{*}{0.484} \\
\hline & No & 42 (82.35\%) & 15 (75.0\%) & \\
\hline \multirow{2}{*}{ Biliary atresia } & Yes & 07 (13.73\%) & $02(10.0 \%)$ & \multirow{2}{*}{0.671} \\
\hline & No & 44 (86.27\%) & $18(90.0 \%)$ & \\
\hline
\end{tabular}

Table-II. Causes of portal hypertension with respect to gender.

\begin{tabular}{|c|c|c|c|c|}
\hline & & $\leq 25000(n=45)$ & $>25000(n=26)$ & P-Value \\
\hline \multirow{2}{*}{ Portal vein thrombosis } & Yes & $33(73.33 \%)$ & $15(57.69 \%)$ & \multirow{2}{*}{0.175} \\
\hline & No & 12 (26.67\%) & 11 (42.31\%) & \\
\hline \multirow{2}{*}{ Liver cirrhosis } & Yes & 09 (20.0\%) & $05(19.23 \%)$ & \multirow{2}{*}{0.937} \\
\hline & No & $36(80.0 \%)$ & $21(80.77 \%)$ & \\
\hline \multirow{2}{*}{ Biliary atresia } & Yes & 03 (6.67\%) & 06 (23.08\%) & \multirow{2}{*}{0.045} \\
\hline & No & 42 (93.33\%) & $20(76.92 \%)$ & \\
\hline
\end{tabular}

Table-III. Causes of portal hypertension with respect to monthly income.

\begin{tabular}{|c|c|c|c|c|}
\hline & & Rural $(n=53)$ & Urban $(n=18)$ & P-Value \\
\hline \multirow{2}{*}{ Portal vein thrombosis } & Yes & 38 (71.70\%) & 10 (55.56\%) & \multirow{2}{*}{0.206} \\
\hline & No & 15 (28.30\%) & 08 (44.44\%) & \\
\hline \multirow{2}{*}{ Liver cirrhosis } & Yes & 09 (16.98\%) & 05 (27.78\%) & \multirow{2}{*}{0.320} \\
\hline & No & 44 (83.02\%) & 13 (72.22\%) & \\
\hline \multirow{2}{*}{ Biliary atresia } & Yes & $06(11.32 \%)$ & 03 (16.67\%) & \multirow{2}{*}{0.556} \\
\hline & No & 47 (88.68\%) & 15 (83.33\%) & \\
\hline
\end{tabular}

Table-IV. Causes of portal hypertension with respect to residential status.

\begin{tabular}{|c|c|c|c|c|}
\hline & & Illiterate $(n=21)$ & Literate $(n=50)$ & P-Value \\
\hline \multirow{2}{*}{ Portal vein thrombosis } & Yes & 15 (71.43\%) & $33(66.0 \%)$ & \multirow{2}{*}{0.656} \\
\hline & No & 06 (28.57\%) & $17(34.0 \%)$ & \\
\hline \multirow{2}{*}{ Liver cirrhosis } & Yes & $11(52.38 \%)$ & 03 (14.29\%) & \multirow{2}{*}{0.456} \\
\hline & No & 39 (47.62\%) & $18(85.71 \%)$ & \\
\hline \multirow{2}{*}{ Biliary atresia } & Yes & 03 (14.29\%) & $06(12.0 \%)$ & \multirow{2}{*}{0.792} \\
\hline & No & 18 (85.71\%) & $44(88.0 \%)$ & \\
\hline
\end{tabular}

Table-V. Causes of portal hypertension with respect to mother's educational level.

\begin{tabular}{|c|c|c|c|c|}
\hline & & $\geq 3$ Months $(n=43)$ & $>3$ Months $(n=28)$ & P-Value \\
\hline \multirow{2}{*}{ Portal vein thrombosis } & Yes & 35 (71.43\%) & $13(66.0 \%)$ & \multirow{2}{*}{0.002} \\
\hline & No & 08 (28.57\%) & $15(34.0 \%)$ & \\
\hline \multirow{2}{*}{ Liver cirrhosis } & Yes & $10(52.38 \%)$ & 04 (14.29\%) & \multirow{2}{*}{0.353} \\
\hline & No & 33 (47.62\%) & $24(85.71 \%)$ & \\
\hline \multirow{2}{*}{ Biliary atresia } & Yes & 07 (14.29\%) & $02(12.0 \%)$ & \multirow{2}{*}{0.258} \\
\hline & No & 36 (85.71\%) & $26(88.0 \%)$ & \\
\hline
\end{tabular}

Table-IV. Causes of portal hypertension with respect to duration of disease. 


\section{DISCUSSION}

A variety of liver as well as vascular diseases are found to contribute to $\mathrm{PH}$ among children. ${ }^{10}$ Most effective way of preventing and managing $\mathrm{PH}$ and its complications are vital for improved outcomes in the affected cases. $\mathrm{PH}$ among children can lead to serious morbidity and is considered a major indication for liver transplantation. ${ }^{11,12}$

In the present study, PVT was noted to be the most common cause $(67.61 \%)$ of $\mathrm{PH}$, followed by liver cirrhosis (19.72\%) and biliary atresia (12.68\%). In a study from Iran on 45 children, most common causes of intrahepatic $\mathrm{PH}$ were seen to be cryptogenic cirrhosis (26.6\%), biliary atresia (24.4\%), and Wilson's disease (17.7\%). ${ }^{9}$ A study from India reported commonest causes of $\mathrm{PH}$ among children to be EHPVO and liver cirrhosis. EHPVO has been labeled as a main cause of $\mathrm{PH}$ in children by other researchers as well. ${ }^{13}$ Grimaldi et al found cirrhosis and congenital hepatic fibrosis to be the most common cause of $\mathrm{PH}$ in children. ${ }^{14}$ All these studies indicate variety in the causes found for $\mathrm{PH}$ among children. Regional variation is also evident with the findings about causes of $\mathrm{PH}$ among children. Researchers from the western countries ${ }^{15,16}$ have found intrahepatic $\mathrm{PH}$ to be more common in the pediatric age groups while studies from South Asia ${ }^{17}$ present extra-hepatic $\mathrm{PH}$ to be more common.

A local study including 408 children with $\mathrm{PH}$ found PVT to be the most common underlying etiology (74.2\%) while chronic liver disease was the second most common finding $(18.1 \%) .{ }^{18}$ In another study Bangladesh, $80 \%$ of the children were noted to have $\mathrm{PH}$ due to pre-hepatic causes. ${ }^{19}$ Poddar $U$ et al ${ }^{20}$ from India found extrahepatic portal venous obstruction to be the most common etiology of $\mathrm{PH}$ in children. In paediatric age group pre hepatic $\mathrm{PH}$ is common accounting for $30-50 \%$ of cases of variceal bleeding. It is estimated that $90 \%$ of the block occurring in the EHPVO is at the site of portal vein obstruction with $10 \%$ of the total blockage at the splenoportal axis. $^{21}$

As PVT was noted to be the most common cause of $\mathrm{PH}$ in the present study, PVT can have various underlying etiologies. PVT has traditionally been linked to conditions like trauma, intra-abdominal sepsis, and umbilical sepsis but still more than half of the cases with PVT are found to have unknown etiology. ${ }^{22,23}$

There were few limitations of our study. This was a single center study with a comparatively small sample size. We also could not identify the underlying etiologies behind most common causes of $\mathrm{PH}$ like $\mathrm{PVH}$ and cirrhosis. As the literature suggests that variation exists regarding cause of $\mathrm{PH}$ among children, further studies involving multiple centers and larger sample size should be conducted so that the results can be more generalized for the guidance of clinicians dealing $\mathrm{PH}$ among children.

\section{CONCLUSION}

This study concluded that that portal vein thrombosis is the most common cause of portal hypertension in children followed by liver cirrhosis and biliary atresia. So, we recommend that proper screening of causes of portal hypertension should be done in these particular patients to take proper management and thus improves the outcome of these particular patients.

\section{Acknowledgement}

The authors would like to Muhammad Aamir (Research Consultant) for his volunteer support in statistical analysis of this research.

\section{Copyright $@ 31$ Aug, 2020.}

\section{REFERENCES}

1. Vogel CB. Pediatric portal hypertension: A review for primary care. Nurse Pract. 2017; 42(5):35-42.

2. Grammatikopoulos T, McKiernan PJ, Dhawan A. Portal hypertension and its management in children. Arch Dis Child. 2018; 103(2):186-91.

3. Young V, Rajeswaran S. Management of portal hypertension in the pediatric population: A primer for the interventional radiologist. Semin Intervent Radiol. 2018; 35(3):160-4. 
4. hodayar-Pardo P, Peña Aldea A, Ramírez González A, Meseguer Carrascosa A, Calabuig Bayo C. Very early presentation of extrahepatic portal vein obstruction causing portal hypertension in an Infant: Uncertainties in the management and therapeutic limitations. Case Rep Gastroenterol 2016; 10:360-365.

5. Marques F, Bellomo-Brandao MA, Hessel G, de Alcantara RV, Ferreira ML. Evaluation of growth and nutritional status in children and adolescents with extrahepatic portal vein obstruction and portal hypertension. Revista de Nutrição 2017; $30(4): 455-461$.

6. Giouleme O, Theocharidou E. Management of portal hypertension in children with portal vein thrombosis. J Pediatr Gastroenterol Nutr. 2013; 57(4):419-25.

7. Mileti E, Rosenthal P. Management of portal hypertension in children. Curr Gastroenterol Rep. 2011; 13(1):10-6.

8. Harmanci O, Bayraktar Y. Portal hypertension due to portal venous thrombosis: Etiology, clinical outcomes. World J Gastroenterol. 2007; $13(18): 2535-40$.

9. Imanieh $\mathrm{MH}$, Dwhghani SM, Khushkhui $M$, Malekpour A. Etiology of portal hypertension in children: A single center's experiences. Middle East J Dig Dis. 2012; 4(4):206-10.

10. Mahajan A, Ghildiyal RG, Karnik P. Clinicopathological correlation of portal hypertension in children and management strategies. Int J Biomed Adv Res 2018; 9(2):70-5.

11. Selvaggi G, Weppler D, Nishida S, Moon J, Levi D, Kato T, Tzakis AG. Ten-year experience in portocaval hemitransposition for liver transplantation in the presence of portal vein thrombosis. Am J Transplant. 2007; 7:454-460.

12. Gómez-Gutierrez M, Quintela J, Marini M, Gala B, Suarez F, Cao I, Sellés CC, Aguirrezabalaga J, Otero $A$, Mosteiro $S$. Portal vein thrombosis in patients undergoing orthotopic liver transplantation: Intraoperative endovascular radiological procedures. Transplant Proc. 2005; 37:3906-3908.
13. Simon EG, Joseph A, George B, Zachariah UG, Jeyamani R, Eapen C. et al. Aetiology of paediatric portal hypertension-experience of a tertiary care Centre in South India. Trop Doct. 2009; 39:42-4.

14. Grimaldi C, de Ville de Goyet J, Nobili V. Portal hypertension in children. Clin Res Hepatol Gastroenterol. 2012; 36:260-1.

15. Maksoud JG, Goncalves MEP, Porta G, Miura I, Velhote MCP. The endoscopic and surgical management of portal hypertension in children: Analysis of 123 cases. J Pediatr Surg. 1991; 26:178-81.

16. Gonçalves MEP, Cardoso SR, Maksoud JG. Prophylactic sclerotherapy in children with esophageal varices: Long-term results of a controlled prospective randomized trial. J Pediatr Surg. 2000; 35:401-5.

17. Yachha SK. Portal hypertension in children: An Indian perspective. J Gastroenterol Hepatol. 2002; 17(Suppl-3):S228-31.

18. Cheema HA, Saeed A, Parkash A, Suleman $H$, Fayyaz Z. Etiology and management of esophageal varices in children: Our experience at tertiary care hospital. Pak Pediatr J. 2014; 38:223-9.

19. Mahmud S, Ahmed SS, Gulshan J, Tasneem F. Etiology of portal hypertension in children-an experience in a tertiary Centre of Bangladesh. Bangladesh J Child Health 2015; 39(1):14-7.

20. Poddar U, Thapa BR, Rao KLN, Singh K. Etiological spectrum of esophageal varices due to portal hypertension in Indian children: Is it different from the West? J Gastroenterol Hepatol. 2008; 23:1354-7.

21. Sarin SK, Agarwal SR. Extrahepatic portal vein obstruction. Semin Liver Dis 2002; 22:43-58.

22. Stringer MD, Heaton ND, Karani J, Olliff S, Howard ER. Patterns of portal vein occlusion and their aetiological significance. $\mathrm{Br} J$ Surg. 1994; 81:1328-1331.

23. Orozco H, Takahashi T, Mercado MA, Prado E, Chan C. Surgical management of extrahepatic portal hypertension and variceal bleeding. World J Surg. 1994; 18:246-250. 


\section{AUTHORSHIP AND CONTRIBUTION DECLARATION}

\begin{tabular}{|c|l|l|l|}
\hline Sr. \# & \multicolumn{1}{|c|}{ Author(s) Full Name } & \multicolumn{1}{|c|}{ Contribution to the paper } & Author(s) Signature \\
\hline 1 & Kausar Aftab & $\begin{array}{l}\text { Data collection, Data } \\
\text { analysis. } \\
\text { Methodology, Drafting. }\end{array}$ \\
\hline 3 & Asim Khurshid & Ayesha Fayyaz & $\begin{array}{l}\text { Study Concept, Proof } \\
\text { reading. } \\
\text { Literature review, } \\
\text { Discussion. }\end{array}$ \\
\hline 4 & Irum Jabeen & Agre caysis \\
\hline
\end{tabular}

